\title{
Oxygen application by a nasal probe prevents hypoxia but not rebreathing of carbon dioxide in patients undergoing eye surgery under local anaesthesia
}

\author{
Andreas Schlager, Thomas J Luger
}

\begin{abstract}
Backgroundlaim-Hypoxia and carbon dioxide rebreathing are potential problems during eye surgery in spontaneously breathing patients. The aim of the present study was to determine effectiveness of nasal application of oxygen to prevent hypoxia and carbon dioxide accumulation in spontaneously breathing patients undergoing cataract surgery.

Methods-Oxygenation and carbon dioxide rebreathing were examined in 40 elderly patients using two different methods of oxygen supply-nasal $v$ ambient air-with a constant flow of $21 / \mathrm{min}$. Partial pressure of carbon dioxide under ophthalmic drapes, transcutaneous pressure of carbon dioxide, and the respiratory rate were measured during 25 minutes while oxygen was supplied via a nasal cannula or into the ambient air under the drapes.

Results-In both groups carbon dioxide accumulation under the drapes, carbon dioxide rebreathing, tachypnoea, and an increase in peripheral oxygen saturation occurred. No significant differences were found between the two methods.

Conclusion-Nasal application of oxygen prevented hypoxia but did not prevent carbon dioxide accumulation in patients undergoing eye surgery under retrobulbar anaesthesia. Additionally, as a side effect when using nasal probes, irritation of the nose was described in half of the patients investigated.
\end{abstract}

(Br F Ophthalmol 2000;84:399-402)

Department of Anaesthesia and General Intensive Care Medicine, Division of Anaesthesia, The Leopold Franzens University of Innsbruck, Austria A Schlager

T J Luger

Correspondence to: Ing Dr Andreas Schlager, Department of Anaesthesia and General Intensive Care Medicine, Anichstrasse 35 , A-6020 Innsbruck, Austria

Accepted for publication 8 December 1999
During eye surgery the patient's head is covered with ophthalmic drapes. Eye surgery performed in spontaneously breathing patients under local anaesthesia poses the danger of hypoxia and rebreathing of carbon dioxide.

Fresh gas or oxygen supplementation under the drapes prevents hypoxia in such patients, ${ }^{12}$ but carbon dioxide exhaled by the patient escapes only partially through the ophthalmic drapes. The result is an increase in carbon dioxide in the ambient air surrounding the patient's head. ${ }^{3-5}$ This causes an increase in arterial partial carbon dioxide pressure and thus tachypnoea of the patients. ${ }^{346-8}$

In contrast with these findings, other investigators reported that when oxygen support was provided via a nasal probe no carbon dioxide rebreathing occurred in the patients. ${ }^{2}$
Until now several different methods, such as suction or high flow fresh gas supply, have been used to prevent carbon dioxide accumulation under ophthalmic drapes. ${ }^{3589}$ If nasal fresh gas application is sufficient to prevent carbon dioxide rebreathing, this method will be the simplest means to prevent carbon dioxide accumulation in patients undergoing eye surgery under local anaesthesia.

Therefore, our study was performed to examine the efficacy of nasal oxygen supply in preventing carbon dioxide rebreathing in spontaneously breathing geriatric patients undergoing eye surgery under retrobulbar anaesthesia.

\section{Material and methods}

The ethics committee of Innsbruck University approved the study protocol. After receiving written informed consent, 40 unpremedicated patients (ASA 1-3) scheduled for cataract surgery under retrobulbar anaesthesia were examined in a randomised single blinded manner. Patients with pre-existing pulmonary disease, psychological, or neurological disorders were excluded from the study. Patients needing intraoperative sedation or additional opiate analgesia and patients who developed psychological problems during the operation were not included in the evaluation of data. All patients were allowed solid food or clear fluids until 8 hours before anaesthesia. On the morning of the operation patients were allowed to take all previously prescribed oral medications except diuretics and sedatives.

After performing retrobulbar anaesthesia a large drape was placed over each patient, fully covering him except for the head. Then the patient's head was covered with a sterile cotton drape $(100 \times 100 \mathrm{~cm})$ having a central, circular aperture ( $80 \mathrm{~mm}$ in diameter) over the eye on which the operation was to be performed. An ophthalmic plastic drape (Steri Drape 1024, $3 \mathrm{M}$ ) measuring $46 \times 39 \mathrm{~cm}$ was put over this cotton drape. Because the drapes used in our study were loosely put over the patient's head, no closed environment was created under the drapes. Owing to several gaps between the drapes and the patient's head room air reached the patient's face ("semiclosed" environment). As shown in Figure 1 a specially designed distance holder was used to prevent contact of the drapes with the mouth and nose and to make a cavity under the drapes. ${ }^{9} 10$

The study patients were randomly allocated to one of two groups comprising 20 people each. Immediately after draping the patient's 

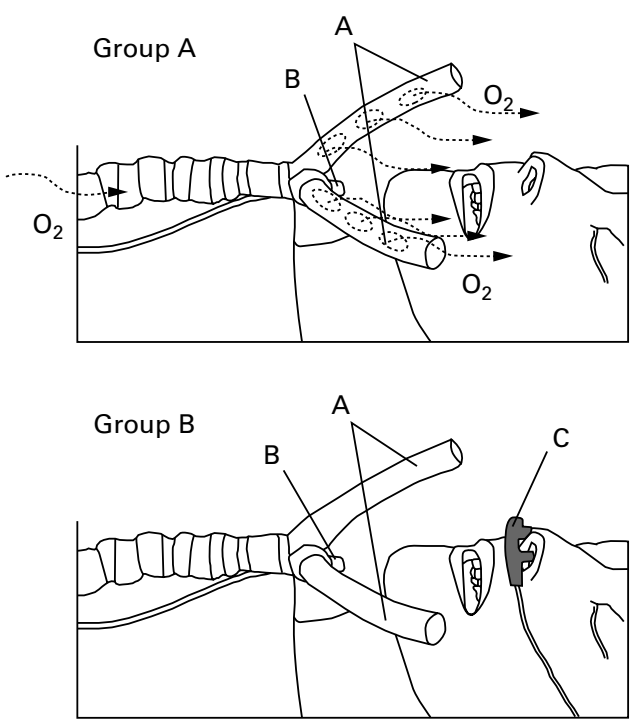

Figure 1 Position of the distance holder $(A)$ between the patient's face and the ophthalmic drapes with apertures for oxygenation of the ambient air in group $A$ and the tip of the carbon dioxide sampling line $(B)$ under the ophthalmic drapes. Nasal cannulae (C) are used in group B for nasal oxygen supply.

head in each group oxygen was insufflated under the drapes with a constant flow of 2 $1 /$ min during the entire surgical course. In group A oxygen was insufflated into the ambient air under the ophthalmic drapes (Fig 1). Oxygen supply in group B was performed with two nasal cannulae (Fig 1, C).

Electrocardiogram, pulse oximetry, and non-invasive blood pressure were established during the total procedure using a standardised monitor (Cardiocap II, Datex, Helsinki, Finland).

VALUES MEASURED

Carbon dioxide concentration in the ambient air surrounding the patient's head under the drapes $\left(\mathrm{pCO}_{2}\right)$

Carbon dioxide was measured with an anaesthesia monitor (Cardiocap Datex, Helsinki, Finland). The tip of the gas sampling line was fixed on a special device (Fig 1, B). To prevent variations in the carbon dioxide curves caused by the patient's breathing, a collection reservoir $(150 \mathrm{ml})$ was placed in the line of the gas sampling tube.

Transcutaneous partial carbon dioxide pressure $\left(\mathrm{P}_{\mathrm{tc}} \mathrm{CO}_{2}\right.$ ) measurement: (TCM 3 Monitor, Radiometer, Copenhagen, Denmark)

Calibration of the measuring electrode was performed at $43^{\circ} \mathrm{C}$ using a standardised $\mathrm{CO}_{2} / \mathrm{O}_{2} / \mathrm{N}_{2}$ gas mixture $\left(5 \% \mathrm{CO}_{2}, 20.9 \% \mathrm{O}_{2}\right.$, $\mathrm{N}_{2}$ balanced). The electrode for $\mathrm{p}_{\mathrm{tc}} \mathrm{CO}_{2}$ measurements was placed on the left lateral thorax at level 4 of the intercostal space.

Respiratory rate ( $R R$ )

Thoracic excursions were counted at each measurement point for a period of 1 minute.

Peripheral oxygen saturation by pulse oximetry $\left(\mathrm{SpO}_{2}\right)$

This was measured with an anaesthesia monitor (Cardiocap, Datex, Helsinki, Finland).
Baseline values were obtained immediately before the patient's head was draped. Additional measurements were taken at 3, 6, 9, 12, 15,20 , and 25 minutes after draping the head, as well as at 5 minutes after complete removal of the remaining drapes.

\section{STATISTICAL ANALYSIS}

Data are expressed as mean (SD). Statistical analysis was performed with SPSS 8.0 (SPSS, Inc, Chicago, IL, USA). To compensate various individual values at the baseline, delta values (value at the measurement timebaseline values) were calculated for $\mathrm{pCO}_{2}$ and $\mathrm{p}_{\mathrm{tc}} \mathrm{CO}_{2}$ values and for the respiratory rate at each measurement point. Overall effects within and between the groups were evaluated using repeated measurement analysis of variance (ANOVA). In the case of significant differences, further comparisons between the groups were made with the unpaired two tailed $t$ test. A $p$ value $\leqslant 0.05$ was considered statistically significant. The Bonferroni test was used for correction of multiple comparison.

\section{Results}

Thirty nine patients were enrolled in the study. One patient in group B was excluded from data analysis because surgery was discontinued for ophthalmic reasons.

Demographic data were similar in both groups (Table 1). During the investigative period no significant differences in mean arterial blood pressure or heart rate were seen, either within or between the groups.

As a side effect, 10 patients in group B complained of a minor irritation caused by the nasal probe, whereas this problem was not seen in the group where oxygen was supplied in the ambient air.

PARTIAL PRESSURE OF CARBON DIOXIDE UNDER THE DRAPES $\mathrm{PCO}_{2}$

When covering the patient's head in both groups, $\mathrm{pCO}_{2}$ values increased significantly $(p<0.001)$ in the ambient air under the drapes and kept increasing until the drapes were removed (Fig 2). In the total course of observation no significant differences were found between the groups.

TRANSCUTANEOUSLY MEASURED PARTIAL PRESSURE OF CARBON DIOXIDE $\left(\mathrm{P}_{\text {tc }} \mathrm{CO}_{2}\right)$ As shown in Figure 2, in both study groups $\mathrm{p}_{\mathrm{tc}} \mathrm{CO}_{2}$ values increased significantly $(\mathrm{p}<0.001)$ immediately after covering the patient's head. After removal of the drapes $\mathrm{p}_{\mathrm{tc}} \mathrm{CO}_{2}$ values again approximated the baseline values.

Comparison between the groups showed no significant differences in $\mathrm{p}_{\mathrm{tc}} \mathrm{CO}_{2}$ values.

Table 1 Demographic data expressed as numbers or mean (SD)

\begin{tabular}{lll}
\hline Demographics & $\begin{array}{l}\text { Oxygenation of the } \\
\text { ambient air }\end{array}$ & Nasal oxygen supply \\
\hline Sex (F/M) & $13 / 7$ & $14 / 5$ \\
Age (years) & $75.8(6.3)$ & $76.8(6.3)$ \\
Body weight (kg) & $63.3(12.1)$ & $65.4(9.0)$ \\
Height (cm) & $161(7.2)$ & $163(7.7)$ \\
\hline
\end{tabular}



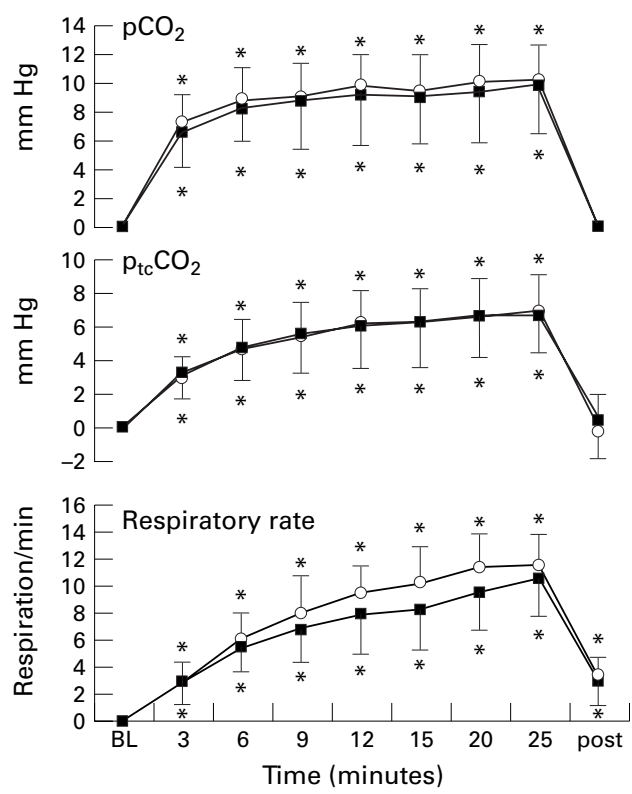

Figure 2 Delta values (mean (SD)) of carbon dioxide partial pressure $\left(\mathrm{PCO}_{2}\right)$ under the drapes, transcutaneous measured partial pressure of carbon dioxide $\left(p_{t c} \mathrm{CO}_{2}\right)$ and of the respiratory rate in spontaneously breathing patients during cataract surgery under retrobulbar anaesthesia.

Baseline values (BL) were measured before draping.

Further values were measured after covering the head. Last measurement (post) was taken 5 minutes after removal of the drapes. ${ }^{*} p \leqslant 0.05$ compared with the baseline. (O) $=$ oxygenation of the ambient air under the drapes, $(\mathbf{\square})=$ nasal oxygen supply

RESPIRATORY RATE

In all groups respiratory rate increased continuously after covering the patient's head. Starting at the third minute after covering the respiratory rate differed significantly $(\mathrm{p}<0.001)$ in all groups and increased throughout in the further course of surgery. No significant differences were found between the two groups. Five minutes after removal of the drapes respiratory rate decreased significantly in all groups compared with the values measured 25 minutes after draping, but was significantly higher $(\mathrm{p}<0.001)$ when compared with the baseline values (Fig 2).

PERIPHERAL OXYGEN SATURATION $\left(\mathrm{Spo}_{2}\right)$

Three minutes after starting oxygen insufflation the $\mathrm{SpO}_{2}$ values rose significantly in all groups without significant differences between the groups (group A: $95.7 \%$ (SD 0.8) to $98.0 \%$ (0.8), $\mathrm{p}=0.003$; group $\mathrm{B}: 95.4 \%$ (1.1) to $98.0 \%$ (0.7), $\mathrm{p}=0.002)$. During the further measurement period $\mathrm{SpO}_{2}$ values were stable. Five minutes after removal of the drapes $\mathrm{Spo}_{2}$ values approximated the baseline values.

\section{Discussion}

Hypoxia and carbon dioxide accumulation are potential problems during eye surgery in spontaneously breathing patients. Supplementation of fresh gas or oxygen prevents hypoxia in the patients. ${ }^{12}$ The problem of carbon dioxide, however, remains. Higher arterial $\mathrm{pCO}_{2}$ values result in raised choroidal blood flow and intraocular pressure. ${ }^{11-13}$ This in turn may complicate the operation and aggravate outcome. ${ }^{14}$
Several other studies have dealt with this hazard. ${ }^{3589}$ Risdall and Geraghty used a nasal probe for oxygen supply and not indirect oxygenation of the air surrounding the patient's head. ${ }^{2}$ In contrast with other investigations they found no carbon dioxide accumulation during eye surgery.

The main findings of our study are that nasal oxygen supplementation and indirect oxygenation of the ambient air each prevents hypoxia but does not prevent carbon dioxide rebreathing in patients undergoing eye surgery under local anaesthesia. The present study examined two different methods of oxygen supply in spontaneously breathing patients undergoing eye surgery. In the group with oxygenation of the ambient air as well as in the group where oxygen was administered via nasal probe carbon dioxide accumulation commenced immediately after draping the patient's head. Therefore, our patients breathed carbon dioxide enriched air during the entire surgical procedure. This caused an increase in the partial transcutaneous carbon dioxide pressure, and tachypnoea consequently occurred in these patients. These findings confirm the results of previously performed studies examining carbon dioxide accumulation under ophthalmic drapes. ${ }^{3-6}$

Our results, however, stand in contrast with previous investigations ${ }^{2}{ }^{15}$ where no carbon dioxide rebreathing occurred in ophthalmic patients undergoing cataract surgery with local anaesthesia. The discrepancy between those results and our study is explained by the difference in the measured variables. Both studies ${ }^{215}$ employed end tidal carbon dioxide measurement, which was performed via a nasal tube, whereas several other studies reporting an increase in carbon dioxide during eye surgery used arterial or transcutaneous partial pressure of carbon dioxide. ${ }^{3468}$ End tidal measurement of carbon dioxide shows two potential problems. To obtain precise results, all patients must breathe exclusively through their nose. Furthermore, if oxygen is administered via a nasal cannula, ${ }^{2}$ exhaled air will be admixed with the supplied oxygen. Therefore, end tidal measurement of carbon dioxide tension may not give a clear picture of carbon dioxide accumulation or carbon dioxide rebreathing. The present study, however, examined carbon dioxide tension in the ambient air under the drapes, transcutaneous $\mathrm{pCO}_{2}$ and the respiratory rate. These variables appear to be a better source of information on carbon dioxide accumulation and carbon dioxide rebreathing. ${ }^{8}$ End tidal carbon dioxide tension alone gives no information on the carbon dioxide concentration in the ambient air under ophthalmic drapes or on an increase in respiratory rate.

With respect to the oxygen flow needed to prevent hypoxia, the present study confirms the main finding of Risdall and Geraghtynamely, that low flow (2 1/min) oxygen supplementation should be provided for all patients undergoing ophthalmic surgery under local anaesthesia. ${ }^{2}$ The present results show that an oxygen flow of $2 \mathrm{l} / \mathrm{min}$ is sufficient to maintain $\mathrm{SpO}_{2}$ values within normal ranges in patients 
without pulmonary disease. $\mathrm{SpO}_{2}$ values rose significantly in all both groups after covering the patient's head and starting oxygen insufflation. Because no significant differences in $\mathrm{SpO}_{2}$ were seen between the two groups, it does not seem to be important which of the two investigated methods was used for oxygen supplementation.

In conclusion, nasal application of oxygen did not prevent carbon dioxide rebreathing in spontaneously breathing patients undergoing eye surgery under local anaesthesia. No difference was seen between oxygen supply performed via nasal cannulae and indirectly into the surrounding air under the drapes. At 2 $1 /$ min oxygen supply was sufficient in both groups to prevent hypoxia in all patients investigated. After consideration of these results and the fact that several patients complained of irritation by the nasal probe, indirect oxygenation of the ambient air under the drapes appears to be more advantageous than oxygen supply via the nasal probe. As seen in previous studies not even fresh gas flows up to $10 \mathrm{l} / \mathrm{min}$ prevented accumulation of carbon dioxide under the drapes. ${ }^{35}$ Therefore, we conclude that suction of the surrounding air combined with a low dose oxygen supply currently seems to be the only adequate means of preventing carbon dioxide accumulation and hypoxia in patients undergoing eye surgery under local anaesthesia. ${ }^{389}$

Additionally, in spontaneously breathing patients undergoing ophthalmic surgery without any provisions for the reduction of carbon dioxide accumulation in the inspired air, routine monitoring with ECG, blood pressure measurements, and pulse oximetry do not seem to be sufficient to detect the development of hypercapnia. We are of the opinion that continuous transcutaneous measurements of carbon dioxide should be discussed particularly in connection with surgery under retrobulbar anaesthesia in sedated patients and in patients with pre-existing pulmonary disorders.

1 Cummings AB, König HL. Effect of oxygen and air inhalation during cataract surgery on blood gas parameters. $\mathcal{F}$ Cataract Refract Surg 1996;22:1236-9.

2 Risdall JE, Geraghty IF. Oxygenation of patients undergoing ophthalmic surgery under local anaesthesia. Anaesthesia 1997;52:492-5.

3 Ramanathan S, Capan L, Chalon J, et al. Minienvironmental control under the drapes during operations on the eyes of conscious patients. Anesthesiology 1978;48:286-8.

4 Schlager A. Accumulation of carbon dioxide under ophthalmic drapes during eye surgery: a comparison of three different drapes. Anaesthesia 1999;54:690-4.

5 Zeitlin GL, Hobin K, Platt J, et al. Accumulation of carbon dioxide during eye surgery. F Clin Anesth 1989;1:262-7.

6 Heinze J, Rohrbach M. General anesthesia vs retrobulbar anesthesia in cataract surgery. A randomized comparison of patients at risk. Anaesthesist 1992;41:481-8.

7 Kobel M, Rifat K, Roth A. Accumulation of carbon dioxide in the operative field in ophthalmic interventions under local anesthesia. Ophthalmologica 1984;188:135-40.

8 Schlager A, Lorenz IH, Luger TJ. Transcutaneous $\mathrm{CO}_{2} / \mathrm{O}_{2}$ and $\mathrm{CO}_{2}$ /air suction in patients undergoing cataract surgery with retrobulbar anaesthesia. Anaesthesia 1998;53: $1212-18$.

9 Schlager A, Staud H. New equipment to prevent carbon dioxide rebreathing during eye surgery under retrobulbar anaesthesia. Br f Ophthalmol 1999;83:1131-4.

10 Schlager A. New support for ophthalmic drapes. Arch Ophthalmol 1999;117:1441-2

11 Hvidberg A, Kessing SV, Fernandes A. Effect of changes in $\mathrm{PCO}_{2}$ and body positions on intraocular pressure during general anaesthesia. Acta Ophthalmol 1981;59:465-75.

12 Petounis AD, Chondreli S, Vadaluka-Sekioti A. Effect of hypercapnoea and hyperventilation on human intraocular pressure general anaesthesia following acetazolamide administration. Br f Ophthalmol 1980;64:422-5.

13 Riva CE, Cranstoun SD, Grunwald JE, et al. Choroidal blood flow in the foveal region of the human ocular fundus. Invest Ophthalmol Vis Sci 1994;35:4273-81.

14 Speaker MG, Guerriero PN, Met JA, et al. A case-control study of risk factors for intraoperative suprachoroidal study of risk factors for intraoperative suprachor
expulsive hemorrhage. Ophthalmology 1991;98:202-9.

15 Michelson G, Naujoks B. $\mathrm{O}_{2}$ administration by a nasal probe mproves respiration in cataract surgery after retrobulbar anesthesia. Ophthalmic Surg 1991;22:615-18. 